UDC 349.444: 347.157

LBC 67.404.212.47-32

\title{
ENSURING THE HOUSING RIGHTS OF VULNERABLE CHILDREN IS AN INTEGRAL COMPONENT OF REALIZING THE SOCIAL FUNCTIONS OF THE STATE
}

\author{
Agnessa O. Inshakova \\ Volgograd State University, Volgograd, Russian Federation \\ Natalya V. Kagalnitskova \\ Volgograd State University, Volgograd, Russian Federation
}

Introduction: ensuring the housing rights of legally free children is the most important element that makes up the complex of actions required for the proper exercising by the state of its social functions. Taking into consideration this thesis and proving it, the authors have set the goal: to analyze the effectiveness of the legal mechanisms and remedies established by the federal and regional legislation. Methods: the methodological basis for this study is a set of scientific methods, among which the methods of systemacity, analysis, and the comparative and legal method are of particular importance. Results: proved in the work the author's position is based on the federal legislation and legislation of the Volgograd region. There has been conducted a thorough analysis of the problems and shortcomings of the legal regulation of one of the most important social spheres of life of a sound society-the provision of housing for legally free children. The authors have argued in favor of the need to consolidate at the federal level, the provisions on determining the residence of legally free children, with the purpose of keeping a file on them. There have been considered the existing legal methods and means aimed at solving the problems connected with the necessity to support the legally free children who are in need of improved housing, and also granting a subsidy to such children for acquiring the necessary set of furniture and payment for utility services, etc. Finding the legal deficiencies and ill-conceived statutory regulations in the field of research aims at the specific proposals generation and recommendations that contribute to better socialization of legally free children by solving their housing problems. Conclusions: as a result of the study there has been conducted the analysis of the statutory procedure for providing improved housing for legally free children, including in the Volgograd region. There have been proposed the ways of overcoming the identified legal deficiencies. There has been proved the necessity of improving the specific provisions of the legislation in the field of protection of the rights of legally free children in terms of the need for realizing the social obligation of the state to provide support to the family, motherhood, fatherhood and childhood enshrined in Article 7 of the Constitution.

Keywords: legally free children, guardianship authorities, suitable dwelling, specialized housing, termination of tenancy agreement in specialized housing, subsidy, residence of minors.

УДК 349.444: 347.157

ББК 67.404.212.47-32

ОБЕСПЕЧЕНИЕ ЖИЛИЩНЫХ ПРАВ СОЦИАЛЬНО УЯЗВИМЫХ ДЕТЕЙ НЕОТЬЕМЛЕМАЯ СОСТАВЛЯЮЩАЯ РЕАЛИЗАЦИИ СОЦИАЛЬНОЙ ФУНКЦИИ ГОСУДАРСТВА

\author{
Агнесса Олеговна Иншакова \\ Волгоградский государственный университет, г. Волгоград, Российская Федерация \\ Наталья Владимировна Кагальницкова \\ Волгоградский государственный университет, г. Волгоград, Российская Федерация
}


Введение: обеспечение жилищных прав детей, оставшихся без попечения родителей, является важнейшим элементом, составляющим комплекс мероприятий, необходимых для полноценного осуществления государством своей социальной функции. С учетом данного тезиса и в обоснование его авторами в работе поставлена цель: проанализировать эффективность установленных федеральным и региональным законодательством правовых механизмов и средств защиты данных прав. Методы: методологическую основу данного исследования составляет совокупность методов научного познания, среди которых особое значение имеют метод системности, метод анализа и сравнительно-правовой метод. Результаты: обоснованная в работе авторская позиция опирается на общефедеральное законодательство и законодательство Волгоградского региона. Проведен тщательный анализ проблем и недостатков правового регулирования одной из самых важных социальных сфер жизнедеятельности здорового общества - обеспечения жильем детей, оставшихся без попечения родителей. Аргументируется необходимость закрепления на федеральном уровне положений об определении места жительства детей, оставшихся без попечения родителей, с целью постановки их на учет. Рассматриваются существующие правовые методы и средства, направленные на решение проблем, связанных с необходимостью обеспечения детей, оставшихся без попечения родителей и нуждающихся в улучшении жилищных условий, а также предоставлением субсидий таким детям с целью приобретения ими необходимого набора мебели, оплаты коммунальных услуг и т. д. Поиск пробелов и недостаточно проработанных нормативных положений в исследуемой сфере направлен на выработку конкретных предложений и рекомендаций, способствующих лучшей социализации в обществе детей, оставшихся без попечения родителей, посредством решения их жилищных проблем. Выводы: в результате исследования проведен анализ законодательно установленного порядка обеспечения детей, оставшихся без попечения родителей, благоустроенным жильем, в том числе и в Волгоградском регионе. Предложены пути преодоления выявленных законодательных недостатков. Обоснована необходимость совершенствования конкретных положений законодательства в области защиты жилищных прав детей, оставшихся без попечения родителей, в контексте необходимости реализации закрепленной в ст. 7 Конституции РФ социальной обязанности государства по обеспечению и поддержке семьи, материнства, отцовства и детства.

Ключевые слова: дети, оставшиеся без попечения родителей, органы опеки и попечительства, благоустроенное жилье, специализированный жилищный фонд, расторжение договора найма жилья в специализированном жилищном фонде, субсидия, место жительства несовершеннолетнего.

\section{Введение}

В любом обществе, даже самом высокоразвитом, могут возникать ситуации, обусловленные как объективными, так и субъективными факторами, когда несовершеннолетние дети остаются без попечения родителей. В соответствии с СК РФ такого несовершеннолетнего, как правило, помещают в социальные учреждения (школы-интернаты, детские дома, дома ребенка), передают в приемные семьи и организации профессионального образования. После окончания социальных учреждений обычно следует служба в Вооруженных силах РФ или поступление в образовательную организацию. Однако возможно и неблагоприятное развитие событий. Неправильно выстроенная несовершеннолетним траектория жизненного пути нередко приводит его в места лишения свободы. Но во всех вышеперечисленных случаях речь идет лишь о временном пребывании там лица из числа детей-сирот и детей, оставшихся без попечения родителей, а значит, проблема от- сутствия места жительства становится неизбежной [6]. Решение проблемы отсутствия у ребенка закрепленного за ним жилья государство должно взять на себя, что является, по мнению авторов, ведущим направлением его социальной политики. Право на жилище является одним из важнейших социально-экономических прав граждан России [10, с. 32], а само жилищное право... имеет целью реализацию государством своей социальной функции [3, с. 9].

\section{Порядок обеспечения}

социальным жильем детей, оставшихся без попечения родителей

В настоящее время законодатель разработал прозрачный механизм финансирования мероприятий по обеспечению жильем детей, оставшихся без попечения родителей [9]. Бюджеты субъектов РФ в обязательном порядке отдельной строкой должны предусматривать бюджетные ассигнования для выполнения данных обязательств. 
Сущностные составляющие механизма обеспечения детей, оставшихся без попечения родителей, в настоящее время определены на уровне федерального законодательства [8]. Также четко обозначены и законодательные полномочия субъектов РФ в данной области, что позволяет исключить возможные злоупотребления на местах.

В Волгоградской области принят пакет документов, регулирующих предоставление жилых помещений данной категории граждан.

В соответствии с Законом Волгоградской области от 5 февраля 2013 г. № 5-ОД «Об обеспечении дополнительных гарантий прав на жилое помещение детей-сирот и детей, оставшихся без попечения родителей, лиц из числа детей-сирот и детей, оставшихся без попечения родителей, в Волгоградской области» законные представители обязаны после достижения указанной категории детей возраста 14 лет предоставить заявление в орган опеки и попечительства о предоставлении благоустроенного жилья. Заявление подается по месту жительства несовершеннолетнего. Надо сказать, что законодатель не уточняет критерии определения места жительства несовершеннолетнего, что влечет за собой некоторые трудности, особенно в тех случаях, когда несовершеннолетний имел одно место жительства, а после определения формы его устройства оно было изменено. Представляется, что, следуя общим правилам об определении места жительства несовершеннолетнего, для целей постановки на учет нуждающихся в жилье в качестве такового должно признаваться место постоянного или преимущественного проживания несовершеннолетнего в соответствии с последней избранной формой устройства, без связи с регистрацией по месту жительства. Если несовершеннолетнего передали под попечительство в возрасте старше 14 лет и его место жительства в связи с этим было изменено, то, полагаем, необходимо предоставить выбор несовершеннолетнему места постановки на учет исходя из сохранения возможных родственных и иных связей. Контроль за подачей такого заявления возлагается на органы опеки и попечительства, которые в случае его отсутствия имеют право самостоятельно включить несовершеннолетнего в список лиц, имеющих право на благоустроенное жилье. Если заявление не было подано, то по окончании попечительства граждане имеют право самостоятельно подать заявление о постановке их на учет в качестве нуждающихся в жилье.

Все лица принимаются на учет в порядке календарной очередности. Но дети-сироты и дети, оставшиеся без попечения родителей, имеют право на внеочередное получение социального жилья. Таким образом, для них существует отдельная очередь. Закон № 159-Ф3 в настоящее время четко закрепил, что право на получение жилого помещения сохраняется до фактического обеспечения жильем, на что неоднократно было указано правоприменительной практикой [4].

Право на получение жилья у детей, оставшихся без попечения родителей, возникает с момента получения ими полной дееспособности по основаниям, предусмотренным гражданским законодательством. При этом обязанность государства обеспечить данных лиц жильем возникает с момента окончания их временного пребывания в социальных, образовательных и иных учреждениях, а также службы в Вооруженных силах РФ. Если у муниципального образования отсутствует необходимое жилье, то должно быть предоставлено временное жилье из специализированного маневренного жилищного фонда [2]. К сожалению, законодатель не устанавливает безусловную обязанность по предоставлению временного жилья, а связывает ее выполнение также с очередностью по предоставлению маневренного жилья [6]. Представляется, что, выполняя свою социальную функцию, государство (субъекты РФ) должно на данный период заключать договоры найма жилых помещений из фонда жилья социального использования (коммерческого найма) в пользу третьего лица. В противном случае социальная функция государства превращается в фикцию и носит декларативный характер.

В настоящее время федеральным законодательством закреплено, что жилое помещение должно предоставляться гражданам по месту их постановки на учет в качестве нуждающихся в черте соответствующего населенного пункта [7]. В соответствии с региональным законодательством в случае невоз- 
можности предоставления гражданину жилого помещения по месту его жительства в границах соответствующего населенного пункта с согласия гражданина ему предоставляется жилое помещение в другом населенном пункте в границах Волгоградской области. По желанию гражданина жилое помещение может быть предоставлено ему по месту осуществления трудовой деятельности в пределах Волгоградской области [2].

Обязательным условием предоставления жилого помещения должна быть его благоустроенность применительно к данному населенному пункту. Жилое помещение предоставляется общей площадью на одного человека в размере 18 кв. м общей площади. Федеральное законодательство, как и региональное законодательство Волгоградской области, не уточняет вопрос о возможности увеличения площади жилья с учетом количества членов семьи гражданина. Полагаем, что в данном случае должны действовать общие правила о предоставлении жилых помещений нуждающимся гражданам и размер жилой площади должен определяться с учетом количества членов семьи. Такой подход согласуется с неоднократно озвученной и подтвержденной позицией судебной практики [5]. Также, на наш взгляд, необходимо учитывать и общие правила о невозможности заселения одной комнаты лицами разного пола, за исключением супругов, а также о предоставлении комнат в коммунальных квартирах только с согласия нанимателей или в случаях, прямо предусмотренных законом.

Данное жилое помещение предоставляется по срочному договору социального найма сроком на пять лет из специализированного жилищного фонда. В течение данного срока орган опеки и попечительства осуществляет контроль за использованием жилых помещений и (или) распоряжением жилыми помещениями, обеспечением их надлежащего санитарного и технического состояния. Порядок осуществления контроля определяется региональным законодательством. Считаем необходимым установить единообразные правила осуществления контроля на федеральном уровне, обозначив, в частности, периодичность проведения проверок и основания внеплановых проверок.
По окончании пятилетнего срока орган опеки обследует жилое помещение, беседует с соседями, запрашивает информацию у правоохранительных органов и в случае выявления «обстоятельств, свидетельствующих о необходимости оказания указанным категориям граждан содействия в преодолении трудной жизненной ситуации» готовит заключение о продлении договора найма сроком еще на пять лет. К таким обстоятельствам в соответствии с законодательством Волгоградской области относятся: «а) неудовлетворительная адаптация нанимателя к самостоятельной жизни, в том числе отсутствие постоянного заработка, иного дохода в связи с незанятостью трудовой деятельностью, наличие отрицательной социальной среды, совершение правонарушений и антиобщественных действий; б) длительная болезнь, инвалидность, препятствующие добросовестному исполнению обязанностей нанимателя, в том числе в связи с нахождением в лечебном или реабилитационном учреждении» [2]. Если вышеуказанные обстоятельства не выявлены, жилое помещение исключается из специализированного жилищного фонда и в отношении его заключается договор социального найма.

Как в федеральном, так и региональном законодательстве отсутствуют директивы относительно возможности установления повторного пятилетнего срока в случаях, когда ситуация не поменялась к лучшему, а, возможно, еще и ухудшилась. В соответствии со ст. 103 ЖК РФ данная категория граждан подлежит выселению из жилого помещения только с предоставлением другого благоустроенного жилого помещения, которое находится в черте населенного пункта. Законодатель, в том числе и региональный, не дает ответа на вопрос: из какого фонда должно быть предоставлено данное благоустроенное жилье? Для решения этого вопроса можно использовать предусмотренные законодателем основания для расторжения договора социального найма по аналогии закона (п. 4 ст. 83 ЖК РФ) с учетом всех гарантий, предоставленных законодателем данной категории граждан. В остальных случаях выселение возможно только с предоставлением благоустроенного жилья путем заключения договора социального найма [1]. Для реализации данных положений, 
безусловно, потребуются коррективы соответствующих положений ЖК РФ.

\section{Выводы}

Анализ законодательно установленного порядка обеспечения детей, оставшихся без попечения родителей, благоустроенным жильем, в том числе и Волгоградского региона, позволяет говорить как о положительных, так и отрицательных его характеристиках. Так, в частности, считаем положительным закрепление на федеральном уровне обязанности субъектов РФ иметь специальную статью в бюджете относительно обеспечения жильем данной категории граждан; установление на федеральном уровне основных положений по порядку обеспечения жильем детей-сирот; обязательность государственного учета специализированного жилья, выделяемого детям, оставшимся без попечения родителей. В то же время к негативным моментам следует отнести те обстоятельства, что законодателем не определен размер средств, которые выделяются в бюджете; не определен срок использования жилья маневренного фонда; отсутствует определенность относительно административной ответственности за предоставление сиротам жилого помещения, непригодного для проживания, а также за несоблюдение порядка предоставления жилья. Рекомендуется на уровне федерального законодательства решить вопрос об освобождении от платы за жилое помещение и/или коммунальные услуги или установлении льгот (субсидий), а также о комплектовании жилого помещения необходимым набором мебели. Совершенствование правового регулирования в области защиты жилищных прав детей, оставшихся без попечения родителей, в указанном направлении будет являться прямой реализацией закрепленной в ст. 7 Конституции РФ социальной обязанности государства по обеспечению государственной поддержки семьи, материнства, отцовства и детства.

\section{СПИСОК ЛИТЕРАТУРЫ}

1. Жилищный кодекс Российской Федерации от 29 дек. 2004 г. № 188-Ф3 : (ред. от 6 июля 2016 г.) // Собрание законодательства РФ. - 2005. - 3 янв. № 1 (ч. 1). - Ст. 14.
2. Закон Волгоградской области «Об обеспечении дополнительных гарантий прав на жилое помещение детей-сирот и детей, оставшихся без попечения родителей, лиц из числа детей-сирот и детей, оставшихся без попечения родителей, в Волгоградской области» от 5 февр. 2013 г. № 5-ОД : (ред. от 11 мая 2016 г.) // Волгоградская правда. - 2013. 8 февр. (№ 23).

3. Иншакова, А. О. Жилищное право в доктрине, национальной правовой и законодательной системе / А. О. Иншакова, Н. В. Кагальницкова // Вестник Волгоградского государственного университета. Серия 5, Юриспруденция. - 2016. - № 3 (32). - C. 9-15.

4. Обзор практики рассмотрения судами дел, связанных с обеспечением детей-сирот и детей, оставшихся без попечения родителей, лиц из числа детей-сирот и детей, оставшихся без попечения родителей, жилыми помещениями : (утв. Президиумом Верхов. Суда РФ 20 нояб. 2013 г.) // Бюллетень Верховного Суда РФ. - 2014. - № 3.

5. Определение Верховного Суда РФ от 11 мая 2011 г. № 43-Г11-9. - Доступ из справ.-правовой системы «КонсультантПлюс».

6. Постановление Правительства Волгоградской области «О мерах по реализации Закона Волгоградской области от 05 февраля 2013 г. № 5-ОД "Об обеспечении дополнительных гарантий прав на жилое помещение детей-сирот и детей, оставшихся без попечения родителей, лиц из числа детей-сирот и детей, оставшихся без попечения родителей, в Волгоградской области"» от 19 марта 2013 г. № 109-п : (ред. от 22 апр. 2015 г.) // Волгоградская правда. - 2013. - 27 марта (№ 53).

7. Постановление Правительства РФ «Об утверждении Правил регистрации и снятия граждан Российской Федерации с регистрационного учета по месту пребывания и по месту жительства в пределах Российской Федерации и перечня лиц, ответственных за прием и передачу в органы регистрационного учета документов для регистрации и снятия с регистрационного учета граждан Российской Федерации по месту пребывания и по месту жительства в пределах Российской Федерации» от 17 июля 1995 г. № 713 : (ред. от 5 февр. 2016 г.) // Собрание законодательства РФ. - 1995. - 24 июля. № 30. - Ст. 2939.

8. Федеральный закон «О дополнительных гарантиях по социальной поддержке детей-сирот и детей, оставшихся без попечения родителей» от 21 дек. 1996 г. № 159-Ф3 : (ред. от 3 июля 2016 г.) // Собрание законодательства РФ. - 1996. - 23 дек. № 52 . - Ст. 5880.

9. Федеральный закон «Об общих принципах организации законодательных (представительных) и исполнительных органов государственной влас- 
ти субъектов Российской Федерации» от 6 окт. 1999 г. № 184-Ф3 // Собрание законодательства РФ. - 1999. 18 окт. - № 42. - Ст. 5005.

10. Филиппов, П. М. Принципы социальности жилищного права / П. М. Филиппов, О. А. Ковалева // Вестник Волгоградского государственного университета. Серия 5, Юриспруденция. - 2016. - № 3 (32). - C. 31-37.

\section{REFERENCES}

1. Zhilishchnyy kodeks Rossiyskoy Federatsii ot 29 dek. 2004 g. № 188-FZ : (red. ot 6 iyulya 2016 g.) [Housing Code of the Russian Federation of December 29, 2004 no. 188-FL (ed. of July 6, 2016)]. Sobranie zakonodatelstva RF [Collected Legislation of the Russian Federation], 2005, no. 1 (part 1), art. 14.

2. Zakon Volgogradskoy oblasti «Ob obespechenii dopolnitelnykh garantiy prav na zhiloe pomeshchenie detey-sirot i detey, ostavshikhsya bez popecheniya roditeley, lits iz chisla detey-sirot i detey, ostavshikhsya bez popecheniya roditeley, v Volgogradskoy oblasti» ot 5 fevr. 2013 g. № 5-OD : (red. ot 11 maya 2016 g.) [The Law of the Volgograd Region "On Provision of Additional Guarantees for the Rights to Housing of Orphaned Children and Children Left without Parental Care, Persons from among Orphaned Children and Children Left without Parental Care in the Volgograd region" of February 5, 2013 no. 5-OD (ed. of May 11, 2016)]. Volgogradskaya Pravda, 2013, Feb. 8 (no. 23).

3. Inshakova A.O., Kagalnitskova N.V. Zhilishchnoe pravo v doktrine, natsionalnoy pravovoy i zakonodatelnoy sisteme [Housing Law in the Doctrine of National Legal and Legislative System]. Vestnik Volgogradskogo gosudarstvennogo universiteta. Seriya 5, Yurisprudentsiya [Science Journal of Volgograd State University. Jurisprudence], 2016, no. 3 (32), pp. 9-15.

4. Obzor praktiki rassmotreniya sudami del, svyazannykh s obespecheniem detey-sirot i detey, ostavshikhsya bez popecheniya roditeley, lits iz chisla detey-sirot i detey, ostavshikhsya bez popecheniya roditeley, zhilymi pomeshcheniyami : (utv. Prezidiumom Verkhov. Suda RF 20 noyab. 2013 g.) [Review of Court Practice Regarding the Cases Related to Providing Housing for Orphaned Children and Children Left without Parental Care, Persons from among Orphaned Children and Children Left without Parental Care: (approved by the Presidium of the Supreme Court of the Russian Federation on November 20, 2013)]. Byulleten Verkhovnogo Suda RF, 2014, no. 3.

5. Opredelenie Verkhovnogo Suda RF ot 11 maya 2011 g. № 43-G11-9 [Decision of the Supreme Court of the Russian Federation of May 11, 2011 no. 43-
G11-9]. Access from Reference Legal System "KonsultantPlyus".

6. Postanovlenie Pravitelstva Volgogradskoy oblasti «O merakh po realizatsii Zakona Volgogradskoy oblasti ot 05 fevralya 2013 g. № 5-OD “Ob obespechenii dopolnitelnykh garantiy prav na zhiloe pomeshchenie detey-sirot i detey, ostavshikhsya bez popecheniya roditeley, lits iz chisla detey-sirot i detey, ostavshikhsya bez popecheniya roditeley, v Volgogradskoy oblasti"»» ot 19 marta 2013 g. № 109-p : (red. ot 22 apr. 2015 g.) [The Resolution of the Government of the Volgograd Region "On Measures for Implementing the Law of the Volgograd region of February 5, 2013 № 5-OD ‘On Provision of Additional Guarantees of the Rights to Housing Orphaned Children and Children Left without Parental Care, Persons from among Orphaned Children and Children Left without Parental Care"' of March 19, 2013 no. 109-p: (ed. of April 22, 2015)]. Volgogradskaya Pravda, 2013, March 27 (no. 53).

7. Postanovlenie Pravitelstva RF «Ob utverzhdenii Pravil registratsii i snyatiya grazhdan Rossiyskoy Federatsii s registratsionnogo ucheta po mestu prebyvaniya i po mestu zhitelstva v predelakh Rossiyskoy Federatsii i perechnya lits, otvetstvennykh za priem i peredachu $\mathrm{v}$ organy registratsionnogo ucheta dokumentov dlya registratsii i snyatiya $\mathrm{s}$ registratsionnogo ucheta grazhdan Rossiyskoy Federatsii po mestu prebyvaniya i po mestu zhitelstva v predelakh Rossiyskoy Federatsii» ot 17 iyulya $1995 \mathrm{~g}$. № 713 : (red. ot 5 fevr. 2016 g.) [The Resolution of the Government of the Russian Federation "On Approval of Rules of Registration and Deregistration of Russian Citizens at a Place of Stay and at a Place of Residence within the Russian Federation, and the List of Persons Responsible for the Receipt and Submission of Documents to the Registration Authorities for Registration and Deregistration of Russian Citizens at a Place of Stay and at a Place of Residence within the Russian Federation" of July 17, 1995 no. 713: (ed. of February 5, 2016)]. Sobranie zakonodatelstva $R F$ [Collected Legislation of the Russian Federation], 1995, July 24 (no. 30), art. 2939.

8. Federalnyy zakon «O dopolnitelnykh garantiyakh po sotsialnoy podderzhke detey-sirot i detey, ostavshikhsya bez popecheniya roditeley» ot 21 dek. 1996 g. № 159-FZ : (red. ot 3 iyulya 2016 g.) [Federal Law "On Additional Guarantees on Social Support of Orphaned Children and Children Left without Parental Car" of December 21, 1996 no. 159-FL: (ed. of July 3, 2016)]. Sobranie zakonodatelstva RF [Collected Legislation of the Russian Federation], 1996, December 23 (no. 52), art. 5880.

9. Federalnyy zakon «Ob obshchikh printsipakh organizatsii zakonodatelnykh (predstavitelnykh) i ispolnitelnykh organov gosudarstvennoy vlasti subyektov Rossiyskoy Federatsii» ot 6 okt. 1999 g. 


\section{ГЛАВНАЯ ТЕМА НОМЕРА}

№ 184-FZ [Federal Law “On General Principles of Organization of Legislative (Representative) and Executive State Authorities in the Entities of the Russian Federation" of October 6, 1999 no. 184-FL]. Sobranie zakonodatelstva RF [Collected Legislation of the Russian Federation], 1999, October 18 (no. 42), art. 5005.
10. Filippov P.M., Kovaleva O.A. Printsipy sotsialnosti zhilishchnogo prava [The Social Principles of Housing Law]. Vestnik Volgogradskogo gosudarstvennogo universiteta. Seriya 5, Yurisprudentsiya [Science Journal of Volgograd State University. Jurisprudence], 2016, no. 3 (32), pp. 31-37.

\section{Information About the Authors}

Agnessa O. Inshakova, Doctor of Juridical Sciences, Professor, Head of the Department of Civil and International Private Law, Volgograd State University, the Base Department of the Southern Scientific Center of the Russian Academy of Sciences, Prosp. Universitetsky, 100, 400062 Volgograd, Russian Federation, ainshakova@list.ru, gimchp@volsu.ru.

Natalya V. Kagalnitskova, Candidate of Juridical Sciences, Assistant Professor, the Department of Civil and International Private Law, Volgograd State University, the Base Department of the Southern Scientific Center of the Russian Academy of Sciences, Prosp. Universitetsky, 100, 400062 Volgograd, RussianFederation, lara7@bk.ru, gimchp@volsu.ru.

\section{Информация об авторах}

Агнесса Олеговна Иншакова, доктор юридических наук, профессор, заведующая кафедрой гражданского и международного частного права, Волгоградский государственный университет, базовая кафедра ЮНЦ РАН, просп. Университетский, 100, 400062 г. Волгоград, Российская Федерация, ainshakova@list.ru,gimchp@volsu.ru.

Наталья Владимировна Кагальницкова, кандидат юридических наук, доцент кафедры гражданского и международного частного права, Волгоградский государственный университет, базовая кафедра ЮНЦ РАН, просп. Университетский, 100, 400062 г. Волгоград, Российская Федерация, lara7@bk.ru, gimchp@volsu.ru. 